\title{
Risk of febrile seizures after first dose of measles-mumps- rubella-varicella vaccine: a population-based cohort study
}

\author{
Shannon E. MacDonald PhD RN, Douglas C. Dover MSc, Kimberley A. Simmonds MSc, \\ Lawrence W. Svenson BSc
}

See related commentary on page 812 and at www.cmaj.ca/lookup/doi/10.1503/cmaj.140778

Competing interests: None declared.

This article has been peer reviewed.

Correspondence to: Shannon MacDonald, smacdon@ualberta.ca

CMAJ 2014. DOI:10.1503 /cmaj.140078

\section{ABSTRACT}

Background: The combination measles-mumpsrubella-varicella (MMRV) vaccine currently used in Canada (Priorix-Tetra) may increase the risk of febrile seizures relative to the separate vaccines (MMR and varicella) previously administered. We determined the risk of febrile seizure after the first dose of MMRV, as well as any additional risk for children at high risk for seizures because of pre-existing medical conditions.

Methods: In this retrospective, populationbased cohort study, we compared the risk of seizures after the first dose of MMRV with the risk after same-day administration of separate MMR and varicella vaccines (MMR+V) in children 12 to 23 months of age in the province of Alberta. We deterministically linked vaccination data to health service utilization data for seizures. We used Poisson regression, with adjustment for age and calendar year, to determine the risk for the full cohort and for high-risk children.

Results: The risk of seizures 7 to 10 days after vaccination was twice as high with MMRV as with $M M R+V$ (relative risk [RR] 1.99, 95\% confidence interval $[\mathrm{Cl}]$ 1.30-3.05). The excess absolute risk of seizures was 3.52 seizures per 10000 doses of MMRV relative to MMR+V. In high-risk children, the risk was not differentially higher for MMRV (RR 1.30, 95\% Cl 0.60-2.79).

Interpretation: Despite an increased risk of febrile seizures following MMRV (compared with $M M R+V$ ), the absolute level of risk was small. Policy-makers need to balance these findings with the potential benefits of administering the combination vaccine or determine whether the choice of vaccine rests with clinicians and/or parents.

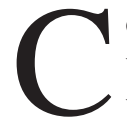
ombination measles-mumps-rubellavaricella (MMRV) vaccines were developed as an alternative to separate MMR and varicella (chickenpox) vaccines. Two such vaccines, with different formulations, are available in North America. ProQuad (Merck) is used in the United States, whereas PriorixTetra (GlaxoSmithKline) is the formulation currently used in Canada. Priorix-Tetra is also used in Australia, Italy and Germany, and it has market authorization in most member states of the European Union. ${ }^{1}$ Postlicensure vaccine safety studies of ProQuad have identified an increased risk of febrile seizures in children 12-23 months old after the first dose ${ }^{2}$ but not after the subsequent preschool dose. ${ }^{3}$

Priorix-Tetra was approved for use in Canada in July $2007 .{ }^{4}$ Currently, 9 of 13 Canadian provinces and territories administer this vaccine as part of their routine childhood immunization schedule. The province of Alberta started admin- istering the vaccine in September 2010, to replace the first dose of MMR and varicella vaccines due at 12 months of age. ${ }^{5}$

Prelicensure clinical trials of Priorix-Tetra indicated that it had a similar safety profile to coadministration of the separate vaccines, except for a higher incidence of fever. ${ }^{4,6}$ Determination of the less common risk of febrile seizures requires postlicensure monitoring in a large population and is an identified research priority of the Canadian National Advisory Committee on Immunization. ${ }^{4}$ Only 1 previous study, conducted in Germany, has assessed febrile seizure risk after Priorix-Tetra, ${ }^{7}$ considering only cases treated in hospital. It is also a priority to determine if the risk is amplified among children with pre-existing medical conditions that may predispose them to seizures. ${ }^{8}$

Our objective was to determine the risk of febrile seizures after the first dose of the combination MMRV vaccine (Priorix-Tetra) adminis- 
tered to children in Alberta, relative to same-day administration of separate MMR and varicella $(\mathrm{MMR}+\mathrm{V})$ vaccines. A secondary objective was to determine if children considered to be at "high risk" for seizures were at increased risk for febrile seizures following administration of the combination vaccine.

\section{Methods}

\section{Study setting and data sources}

Alberta has a population of 4.1 million and an annual birth cohort of over $50000 .{ }^{9}$ The province has a publicly funded, universally available health care system. Registration in the health insurance plan is mandatory for all residents, and the plan covers more than $99 \%$ of the population. Each person registered receives a unique numeric identifier that can be used to assess health service use and to link health records at the individual level. ${ }^{10}$

Routine recommended childhood vaccinations in Alberta are provided at no cost to the recipient and are administered by public health nurses in community-based clinics, according to the schedule set by the Alberta Ministry of Health (see Appendix 1, available at www.cmaj.ca/lookup /suppl/doi:10.1503/cmaj.140078/-/DC1). Individual-level vaccination data are submitted by each health zone to the provincial immunization repository. The repository includes data on specific vaccines administered to all children resident in Alberta, except First Nations children living on reserves, who receive their vaccinations through federally administered programs, and children in the border town of Lloydminster, who receive public health services from the province of Saskatchewan. The repository has data submission guidelines and business rules that promote the completeness and quality of data submissions, such as flagging mismatches between vaccine name and lot number.

Seizure events that involve presentation to the health care system in Alberta can be ascertained from 3 administrative databases: the physician claims database, an electronic fee-for-service system to which all physicians submit billing information; the ambulatory care reporting system, which includes emergency department visits; and the hospital discharge abstracts database. Previous epidemiologic studies ${ }^{11-14}$ have found that these data sources have a high level of completeness and validity. Physicians must submit diagnostic codes (up to 3 per visit) to be reimbursed under the feefor-service insurance plan, and relatively few Alberta physicians $(<7 \%)$ are on alternate payment plans, compared with other Canadian provinces. ${ }^{15}$ The ambulatory care and hospital dis- charge databases feed into the Canadian Institute for Health Information databases and thus meet the institute's mandated quality assurance guidelines. ${ }^{16}$

\section{Study design and population}

In this retrospective population-based cohort study (for the period 2006-2012), we compared the relative risk (RR) of seizures among children aged 12-23 months who received MMRV (administered from mid-2010 onward) and those who received MMR+V (2006 onward). We excluded children who received a dose of any of these vaccines before 12 months of age or who were immunized outside the province. We extracted vaccination data from the immunization repository. We obtained data on seizure events from the physician claims database (International Statistical Classification of Diseases and Related Health Problems [ICD], Ninth Revision, codes $780.3^{*}$ for convulsions) and the ambulatory care and hospital discharge databases (ICD, 10th revision, Canadian version, codes R56.0* for febrile convulsions), using coding consistent with other studies of febrile seizures after vaccination. ${ }^{17-20}$ Coding did not change during the study period. Because we compared seizure incidence in the periods before and immediately after vaccination, we assumed that any increase in frequency of febrile seizure after vaccination was related to the vaccine. We linked seizure data to vaccination data through deterministic matching, using unique lifetime identifiers.

Ethics consent for this study was obtained from the University of Calgary Conjoint Health Research Ethics Board.

\section{Data analysis}

For each vaccine administered, we compared the incidence of seizures in the 42-day "observation period" following administration (comparable with clinical trials of Priorix-Tetra and the postlicensure study of ProQuad ${ }^{2,6,21}$ ) and the 7- to 10day "peak period" (when previous studies have indicated that febrile seizure risk is expected to be highest ${ }^{222}$ ) with the incidence in the 42 days preceding vaccination (control period) using a riskinterval analysis. ${ }^{23}$ To confirm that the defined peak period was valid in our study, we conducted a sensitivity analysis, looking at 9 different risk windows $([5,6,7$ days $] \times[10,11,12$ days $]){ }^{24}$ To avoid counting repeat visits for the same seizure event, we considered only the first seizure within the overall period of observation (from 42 days before to 42 days after vaccination). We conducted Poisson regression, controlling for age and calendar year. We calculated and compared the absolute risk of seizures for MMRV and MMR+V to determine any excess risk of seizures from 
MMRV. All analyses were performed with SAS version 9.2 (SAS Institute).

The primary data analysis included all children in the cohort. The secondary analysis was conducted to determine if high-risk children exhibited a differentially higher risk of seizures following MMRV relative to MMR+V. We defined "highrisk" children (as per previous studies ${ }^{19,25}$ ) as those with a personal history of febrile seizure; seizure disorder; central nervous system injury, infection or neoplasm; encephalopathy; or a progressive, evolving or unstable neurologic condition (as identified from physician claims, emergency department visits or hospital discharges using applicable codes [see Appendix 2, available at www.cmaj.ca /lookup/suppl/doi:10.1503/cmaj.140078/-/DC1]).

Table 1: Number and proportion of vaccine doses administered by time period, age group and risk group in children aged 12-23 months, and number and proportion of incident events of seizure in the cohort and by risk group

\begin{tabular}{|c|c|c|}
\hline \multirow[b]{2}{*}{ Categorization } & \multicolumn{2}{|c|}{ No. $(\%)$ of children* } \\
\hline & $\begin{array}{c}\text { MMRV } \\
n=96686\end{array}$ & $\begin{array}{c}\mathrm{MMR}+\mathrm{V} \\
n=181088\end{array}$ \\
\hline \multicolumn{3}{|l|}{ Doses administered, by calendar year } \\
\hline 2006-2009 & NA & 152985 (84.5) \\
\hline 2010 (MMRV introduced) & $13689(14.2)$ & $27817 \quad(15.4)$ \\
\hline 2011-2012 & $82997(85.8)$ & $286 \quad(0.2)$ \\
\hline \multicolumn{3}{|l|}{ Doses administered, by child's age, mot } \\
\hline 12 & $62782(64.9)$ & 123650 \\
\hline 13 & $15001(15.5)$ & 26273 (14.5) \\
\hline 14 & $7027 \quad(7.3)$ & 11555 \\
\hline 15 & $3603 \quad(3.7)$ & 6212 \\
\hline $16-17$ & $3607 \quad(3.7)$ & 5977 \\
\hline $18-23$ & $4666 \quad(4.8)$ & 7421 \\
\hline \multicolumn{3}{|l|}{ Doses administered, by risk levelt } \\
\hline Low risk & $92570(95.7)$ & 174198 (96.2) \\
\hline High risk $\ddagger$ & $4116 \quad(4.3)$ & $6890 \quad(3.8)$ \\
\hline \multicolumn{3}{|c|}{$\begin{array}{l}\text { Seizure experienced, total cohort and by } \\
\text { risk group, no. (no. per } 10000 \text { doses) }\end{array}$} \\
\hline Prevaccine, $-42 \mathrm{~d}$ to $-1 \mathrm{~d}$ & $151(15.6)$ & $261 \quad(14.4)$ \\
\hline Low risk & $111(12.0)$ & $190 \quad(10.9)$ \\
\hline High risk $\neq$ & $40(97.2)$ & $71(103.0)$ \\
\hline Postvaccine, 0 to $42 \mathrm{~d}$ & $285(29.5)$ & $367 \quad(20.3)$ \\
\hline Low risk & $244(26.4)$ & 303 (17.4) \\
\hline High risk $\ddagger$ & $41(99.6)$ & $64 \quad(92.9)$ \\
\hline Postvaccine, peak risk interval, 7 to $10 \mathrm{~d}$ & $125(12.9)$ & $97 \quad(5.4)$ \\
\hline Low risk & $108(11.7)$ & $(4.2)$ \\
\hline High risk $\ddagger$ & $17(41.3)$ & $24(34.8)$ \\
\hline \multicolumn{3}{|c|}{$\begin{array}{l}\text { Note: } M M R V=\text { measles-mumps-rubella-varicella vaccine, } M M R+V=\text { measles-mumps-rubella } \\
\text { plus varicella vaccine, } N A=\text { not applicable. } \\
\text { *Except where indicated otherwise. } \\
\text { tSignificant difference between vaccine groups ( } p<0.001 \text {, by } \chi^{2} \text { test of difference). } \\
\text { fPrevious medical history that may predispose child to seizures. }\end{array}$} \\
\hline
\end{tabular}

We were unable to identify family history of seizures.

\section{Results}

Our cohort consisted of 277774 children aged 12-23 months who received either MMRV or $\mathrm{MMR}+\mathrm{V}$ in Alberta between 2006 and 2012. The combination vaccine was added to the provincial program in mid-2010, and by 2011 and 2012 most children in the cohort $(99.7 \%)$ were receiving MMRV (Table 1). The difference in age distributions for the groups receiving MMRV and MMR+V was statistically significant but not clinically meaningful: $91.4 \%$ and $92.6 \%$ of children, respectively, received the vaccine between ages 12 and 15 months. Four percent of the children in the cohort were considered at high risk for seizures because of prior medical conditions.

We observed a notable increase in seizure incidence in the 7-10 days after either vaccine combination (Figure 1), which fits with the biologically plausible period for febrile seizures after a measles-containing vaccine. ${ }^{2,22}$ The incidence after $\mathrm{MMR}+\mathrm{V}$ peaked at 2.2 seizures per 10000 doses, whereas the incidence after MMRV was higher, at 5.8 seizures per 10000 doses. Our sensitivity analysis confirmed the validity of the 7- to 10-day postvaccine "peak period" for seizure incidence. The rate of seizures was notably higher in the high-risk group than in the rest of the cohort, both before and after vaccination (Table 1).

The unadjusted and adjusted relative risks for seizures after MMRV and MMR+V, and the ratio between these risks, are reported in Table 2. In the adjusted analysis, there was no differentially increased risk after MMRV compared with $\mathrm{MMR}+\mathrm{V}$ in the 0 - to 42-day observation window (relative risk [RR] 1.21, 95\% confidence interval [CI] 0.93-1.58), but the risk was elevated in the 7- to 10-day peak period (RR 1.99, 95\% CI 1.303.05) (Table 2). The risk of seizures was differentially elevated with MMRV in the low-risk group (RR 2.27, 95\% CI 1.48-3.49) but not the highrisk group (RR 1.30, 95\% CI 0.60-2.79). During the 7- to 10-day peak period, the excess absolute risk of seizures resulting from administration of the MMRV vaccine relative to $\mathrm{MMR}+\mathrm{V}$ was 3.52 seizures per 10000 doses administered (Table 3).

\section{Interpretation}

During the 7- to 10-day peak period, the risk of febrile seizures among children receiving their first dose of MMRV was double that for sameday administration of the separate vaccines. This 
translates to an additional 3.52 seizures per 10000 doses administered, or 1 excess seizure for every 2841 doses administered. Whether this increase is of practical significance is uncertain, as the threshold for acceptable risk may differ among parents, clinicians and policy-makers. The risk after MMRV relative to $M M R+V$ in the low-risk group was essentially similar to that in the full cohort. The risk in the high-risk group was not differentially higher for MMRV, which may be explained by the already-high baseline incidence of seizures in this group. The lack of a differentially increased risk after MMRV in the high-risk group is reassuring and suggests that no additional criteria are needed to guide immunization of this group.

The 2010 statement of the National Advisory Committee on Immunization regarding $\mathrm{MMRV}^{4}$ noted that the lack of evidence of an increase in risk for febrile seizure with MMRV may be due to study sample sizes that were too small to detect a difference. This highlights the need for population-based postlicensure studies of less common adverse events, such as febrile seizures. One such study recently conducted in Germany ${ }^{7}$ compared the risk of febrile seizure after the first dose of Priorix-Tetra with the risk after MMR $+\mathrm{V}$ and/or MMR. The researchers were able to include in their analysis only cases involving hospital admission. Their comparison of MMRV and $\mathrm{MMR}+\mathrm{V}$ showed that the adjusted odds of febrile seizures in the 5- to 12-day postvaccine period ranged from 1.5 (95\% CI $0.8-2.9)$ to 3.5 (95\% CI 0.77-19.0), depending on case definition. The lack of statistical significance may be the result of including children up to age 5 years in the analysis, given that febrile seizures from

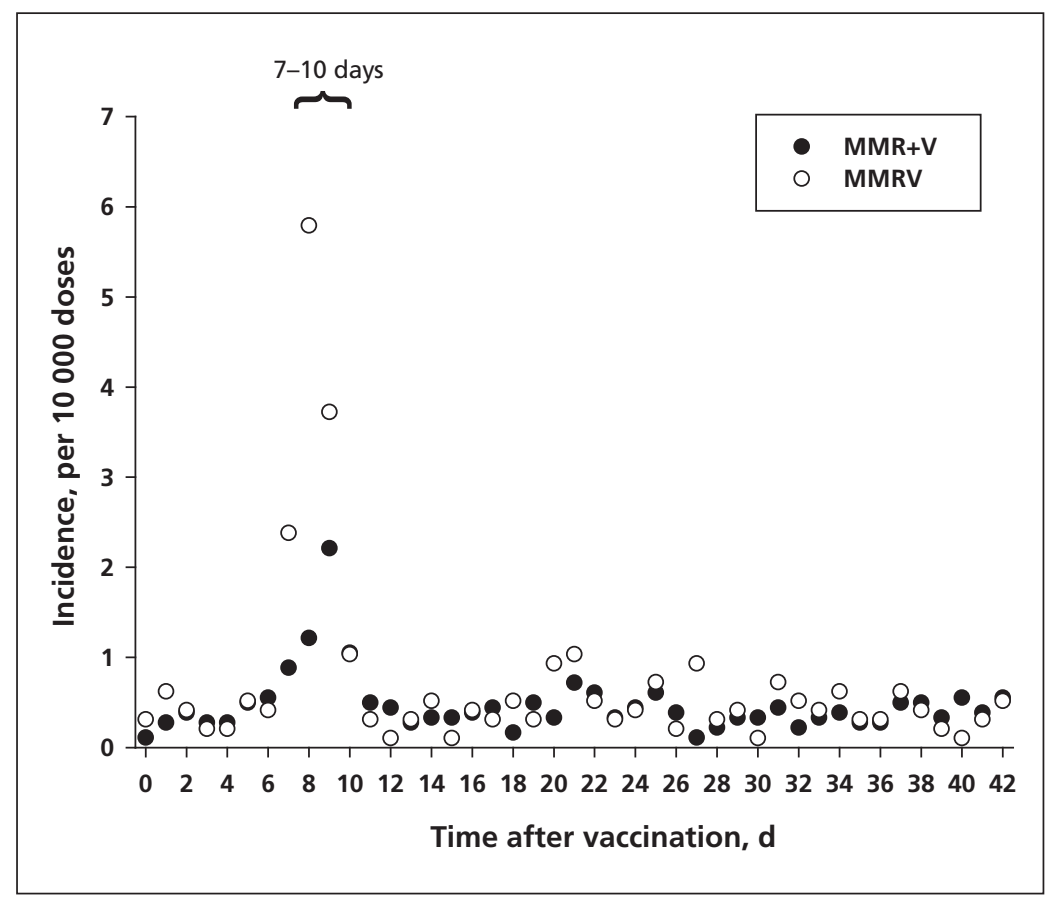

Figure 1: Incidence of febrile seizure following measles-mumps-rubellavaricella (MMRV) combination vaccine or same-day administration of measlesmumps-rubella vaccine with varicella vaccine (MMR+V). The 7- to 10-day peak risk period is indicated.

Table 2: Unadjusted and adjusted* relative risk of seizure following MMRV and MMR+V vaccination, relative to baseline risk over 42 days before vaccination, and relative risk ratio for full cohort and by risk group

\begin{tabular}{|c|c|c|c|c|c|c|}
\hline \multirow[b]{2}{*}{ Postvaccine period } & \multicolumn{2}{|c|}{ MMRV } & \multicolumn{2}{|c|}{$\mathrm{MMR}+\mathrm{V}$} & \multicolumn{2}{|c|}{$\begin{array}{c}\text { RR ratio, } \\
\text { MMRV to } M M R+V\end{array}$} \\
\hline & $\begin{array}{l}\text { Unadjusted } \\
\text { RR }(95 \% \mathrm{Cl})\end{array}$ & $\begin{array}{c}\text { Adjusted RR } \\
(95 \% \mathrm{Cl})\end{array}$ & $\begin{array}{l}\text { Unadjusted } \\
\text { RR }(95 \% \mathrm{CI})\end{array}$ & $\begin{array}{l}\text { Adjusted RR } \\
(95 \% \mathrm{Cl})\end{array}$ & $\begin{array}{l}\text { Unadjusted } \\
(95 \% \mathrm{Cl})\end{array}$ & $\begin{array}{l}\text { Adjusted } \\
(95 \% \mathrm{Cl})\end{array}$ \\
\hline \multicolumn{7}{|c|}{ Full cohort $(n=277774)$} \\
\hline Days 0 to 42 & $\begin{array}{c}1.94 \\
(1.67-2.26)\end{array}$ & $\begin{array}{c}1.80 \\
(1.43-2.27)\end{array}$ & $\begin{array}{c}1.33 \\
(1.16-1.54)\end{array}$ & $\begin{array}{c}1.48 \\
(1.22-1.79)\end{array}$ & $\begin{array}{c}1.45 \\
(1.25-1.70)\end{array}$ & $\begin{array}{c}1.21 \\
(0.93-1.58)\end{array}$ \\
\hline Days 7 to 10 & $\begin{array}{c}9.15 \\
(7.49-11.18)\end{array}$ & $\begin{array}{c}6.57 \\
(4.77-9.05)\end{array}$ & $\begin{array}{c}3.79 \\
(3.04-4.73)\end{array}$ & $\begin{array}{c}3.30 \\
(2.40-4.52)\end{array}$ & $\begin{array}{c}2.41 \\
(1.85-3.15)\end{array}$ & $\begin{array}{c}1.99 \\
(1.30-3.05)\end{array}$ \\
\hline \multicolumn{7}{|c|}{ Low-risk group ( $n=266768$ ) } \\
\hline Days 7 to 10 & $\begin{array}{c}10.86 \\
(8.71-13.53)\end{array}$ & $\begin{array}{c}6.69 \\
(4.90-9.13)\end{array}$ & $\begin{array}{c}3.90 \\
(3.02-5.04)\end{array}$ & $\begin{array}{c}2.94 \\
(2.13-4.07)\end{array}$ & $\begin{array}{c}2.78 \\
(2.07-3.75)\end{array}$ & $\begin{array}{c}2.27 \\
(1.48-3.49)\end{array}$ \\
\hline \multicolumn{7}{|c|}{ High-risk groupt ( $n=11006)$} \\
\hline Days 7 to 10 & $\begin{array}{c}4.30 \\
(2.58-7.16)\end{array}$ & $\begin{array}{c}4.68 \\
(2.49-8.79)\end{array}$ & $\begin{array}{c}3.63 \\
(2.33-5.64)\end{array}$ & $\begin{array}{c}3.61 \\
(2.20-5.93)\end{array}$ & $\begin{array}{c}1.19 \\
(0.64-2.21)\end{array}$ & $\begin{array}{c}1.30 \\
(0.60-2.79)\end{array}$ \\
\hline \multicolumn{7}{|c|}{$\begin{array}{l}\text { Note: } \mathrm{Cl}=\text { confidence interval, } \mathrm{MMRV}=\text { measles-mumps-rubella-varicella vaccine, } \mathrm{MMR}+\mathrm{V}=\text { measles-mumps-rubella vaccine plus varicella vaccine, } \mathrm{RR}=\text { relative } \\
\text { risk. } \\
\text { *Adjusted for calendar year and age. } \\
\text { tOnly } 4 \text { cases of postvaccination seizure were identified in the high-risk group in } 2011 \text {, lower than expected given that about } 10 \text { cases were identified in each of } \\
\text { the other years. Thus, } 2011 \text { was treated as an outlier but was kept in the model by including a separate parameter for this year and its effect on the high-risk } \\
\text { group within the risk interval. }\end{array}$} \\
\hline
\end{tabular}


all causes, including after ProQuad vaccine, ${ }^{3}$ are known to be less common in children 4-6 years of age than in younger children. ${ }^{4}$

Our finding that seizures were twice as common after the first dose of MMRV is consistent with results of the study of ProQuad in the US, ${ }^{2}$ in which the relative risk of seizures was 1.98 (95\% CI 1.43-2.73) in the 7 to 10 days after administration. These findings resulted in the US Advisory Committee on Immunization Practices withdrawing its preference for use of the combination vaccine for the first dose. ${ }^{26}$ This body instead advises immunization providers and parents to consider the benefits and risks of each option before choosing. If there is no parental preference, it recommends that separate MMR and varicella vaccine be administered for the first dose in children 12-47 months of age and that MMRV be given to older children or second-dose recipients. Perhaps a similar recommendation is appropriate for Priorix-Tetra.

Our finding of no difference in seizure risk between MMRV and MMR $+\mathrm{V}$ for the high-risk group concurs with the finding of Klein and colleagues $^{2}$ regarding ProQuad. Although they did not assess RR, they reported that the proportion of children with a personal history of seizures who had postvaccination febrile seizures was similar for those who received MMRV and those who received MMR+V.

\section{Strengths and limitations}

This study had the advantage of using a large population-based cohort in a universal health care system. We were able to capture all vaccination events and medically attended seizure events for the entire population, thus avoiding the sampling bias that may occur with private health insurance data sources, which often exclude lower-income individuals..$^{27,28}$

Although our study did not capture seizures

\begin{tabular}{|lc|}
\hline Table 3: Absolute risk of seizures for full cohort \\
\hline \multicolumn{2}{|c|}{$\begin{array}{c}\text { Absolute risk, } \\
\text { per } 10000 \text { doses }\end{array}$} \\
\hline $\begin{array}{l}\text { Bask } \\
-42 \text { to }-1 \mathrm{~d}\end{array}$ \\
$\begin{array}{l}\text { Postvaccine, with MMRV, } \\
7 \text { to } 10 \mathrm{~d}\end{array}$ \\
$\begin{array}{l}\text { Postvaccine, with MMR+V, } \\
7 \text { to } 10 \mathrm{~d}\end{array}$ \\
\hline $\begin{array}{l}\text { Excess risk for MMRV } \\
\text { relative to MMR+V }\end{array}$ \\
\hline $\begin{array}{l}\text { Note: MMRV = measles-mumps-rubella-varicella vaccine, } \\
\text { MMR+V = measles-mumps-rubella vaccine plus varicella } \\
\text { vaccine. }\end{array}$ \\
\hline
\end{tabular}

for which no medical care was sought, we think it likely that most seizure events in children under the age of 2 years would cause sufficient parental concern to prompt access of health care services. Also, although we did not conduct chart reviews to confirm febrile seizures, seizure events were measured consistently both before and after vaccination for the 2 vaccine types, so calculation of the RRs should have been unbiased. When Klein and colleagues ${ }^{2}$ conducted such chart reviews in their study, the RR changed from 1.98 to 2.04 .

Because administration of $\mathrm{MMR}+\mathrm{V}$ was replaced by MMRV in 2010, our comparison is susceptible to a historical effect. In addition to adjusting for calendar year in our analysis, we examined the baseline incidence of seizures by calendar year (see Appendix 3, available at www .cmaj.ca/lookup/suppl/doi:10.1503/cmaj.140078/ -/DC1) and found no historical trend. Also, although the 13-valent pneumococcal conjugate vaccine was added to the 12-month vaccination schedule in 2010 (see Appendix 1), the risk window for febrile seizures after this vaccine and its predecessor, the 7-valent pneumococcal conjugate vaccine (both inactivated vaccines), is less than 7 days after vaccination ${ }^{20,29-31}$ and thus would not confound our finding of an increased risk in days 7 to 10 .

It is possible that limiting our cohort to vaccinated children might have influenced the rate of seizures in the prevaccine period if unvaccinated children had a different incidence of seizures than their vaccinated peers (i.e., a "healthy vaccinee effect"). Although it is possible that such an effect might have altered the $\mathrm{RR}$ of seizures for both MMRV and MMR+V, it would not have affected the ratio between the 2 (as both groups would be equally biased), which was our primary measure of interest. The available population-level data did not permit identification of antipyretic use, which might have altered incidence of high fever and subsequent febrile seizures.

\section{Conclusion}

Combining MMR and varicella into a single vaccine decreases pain for children and distress for parents, thus addressing common barriers to vaccine uptake, ${ }^{6,32-34}$ and may improve vaccine coverage levels and decrease immunization delivery costs. ${ }^{35}$ These potential benefits must be balanced by the increased risk (albeit small) of febrile seizures with the combination vaccine. Febrile seizures are typically self-limiting and rarely have long-term effects, ${ }^{36}$ but they can be extremely distressing for parents, may precipitate acute care visits and may undermine confidence in immu- 
nization programs. ${ }^{4,37}$ It is a matter for debate whether the choice of separate versus combination vaccine is a policy decision or a choice for parents to make in consultation with their vaccination provider. If MMRV continues to be offered for first-dose administration, it might be advisable to counsel parents regarding antipyretic use if children experience a fever within the peak risk period.

\section{References}

1. Summary of European Union decisions on marketing authorisations in respect of medicinal products from 1 June 2013 to 31 July 2013. Off J Eur Union 2013;56(C250):30-43.

2. Klein NP, Fireman B, Yih WK, et al. Measles-mumps-rubellavaricella combination vaccine and the risk of febrile seizures. Pediatrics 2010;126:e1-8.

3. Klein NP, Lewis E, Baxter R, et al. Measles-containing vaccines and febrile seizures in children age 4 to 6 years. Pediatrics 2012 129:809-14.

4. Statement on measles-mumps-rubella-varicella vaccine. Can Commun Dis Rep 2010;36(ACS-9):1-22.

5. Routine immunization schedule. Edmonton (AB): Alberta Health; 2013. Available: www.health.alberta.ca/health-info/immroutine-schedule.html (accessed 2013 Dec. 20).

6. Czajka H, Schuster V, Zepp F, et al. A combined measles, mumps, rubella and varicella vaccine (Priorix-Tetra): immunogenicity and safety profile. Vaccine 2009;27:6504-11.

7. Schink T, Holstiege J, Kowalzik F, et al. Risk of febrile convulsions after MMRV vaccination in comparison to MMR or MMR+V vaccination. Vaccine 2014;32:645-50.

8. Hviid A. Measles-mumps-rubella-varicella combination vaccine increases risk of febrile seizure. J Pediatr 2011;158:170.

9. Interactive Health Data Application. Edmonton (AB): Alberta Health; 2013. Available: www.ahw.gov.ab.ca/IHDA_Retrieval/ (accessed 2014 Jan. 6)

10. Russell ML, Schopflocher DP, Svenson L, et al. Secular trends in the epidemiology of shingles in Alberta. Epidemiol Infect 2007; 135:908-13.

11. Quan H, Khan N, Hemmelgarn BR, et al. Validation of a case definition to define hypertension using administrative data. Hypertension 2009;54:1423-8.

12. Chen $\mathrm{G}$, Khan N, Walker R, et al. Validating ICD coding algorithms for diabetes mellitus from administrative data. Diabetes Res Clin Pract 2010;89:189-95.

13. Reid AY, St Germaine-Smith C, Liu M, et al. Development and validation of a case definition for epilepsy for use with administrative health data. Epilepsy Res 2012;102:173-9.

14. Jetté N, Reid AY, Quan H, et al. How accurate is ICD coding for epilepsy? Epilepsia 2010;51:62-9.

15. Lix LMW, Walker R, Quan H, et al. Features of physician services databases in Canada. Chronic Dis Inj Can 2012;32:186-93.

16. Quality assurance processes applied to the Discharge Abstract and Hospital Morbidity databases. Ottawa (ON): Canadian Institute of Health Information; 2008.

17. Quantin C, Benzenine E, Velten M, et al. Self-controlled case series and misclassification bias induced by case selection from administrative hospital databases: application to febrile convulsions in pediatric vaccine pharmacoepidemiology. Am J Epidemiol 2013;178:1731-9.

18. Hanf M, Quantin C, Farrington P, et al. Validation of the French national health insurance information system as a tool in vaccine safety assessment: application to febrile convulsions after pediatric measles/mumps/rubella immunization. Vaccine 2013;31:5856-62.

19. Vestergaard M, Hviid A, Madsen KM, et al. MMR vaccination and febrile seizures: evaluation of susceptible subgroups and long-term prognosis. JAMA 2004;292:351-7.

20. Tse A, Tseng HF, Greene SK, et al. Signal identification and evaluation for risk of febrile seizures in children following trivalent inactivated influenza vaccine in the Vaccine Safety Datalink Project, 2010-2011. Vaccine 2012;30:2024-31.

21. Product monograph: Priorix-Tetra. Combined measles, mumps, rubella and varicella vaccine, live, attenuated. Mississauga (ON): GlaxoSmithKline; 2013. Available: www.gsk.ca/english/docs -pdf/product-monographs/Priorix-tetra.pdf (accessed 2014 Jan. 6).

22. Rowhani-Rahbar A, Fireman B, Lewis E, et al. Effect of age on the risk of fever and seizures following immunization with measlescontaining vaccines in children. JAMA Pediatr 2013;167:1111-7.
23. Glanz JM, McClure DL, Xu S, et al. Four different study designs to evaluate vaccine safety were equally validated with contrasting limitations. J Clin Epidemiol 2006;59:808-18.

24. Akaike H. Likelihood of a model and information criteria. J Econom 1981;16:3-14.

25. Jacobsen SJ, Ackerson BK, Sy LS, et al. Observational safety study of febrile convulsion following first dose MMRV vaccination in a managed care setting. Vaccine 2009;27:4656-61.

26. Use of combination measles, mumps, rubella, and varicella vaccine: recommendations of the Advisory Committee on Immunization Practices (ACIP). MMWR Recomm Rep 2010;59(RR-3):1-12.

27. Russell ML, Dover DC, Simmonds KA, et al. Shingles in Alberta: before and after publicly funded varicella vaccination. Vaccine 2013 Oct. 4. [Epub ahead of print]

28. Donahue JG, Kieke BA, Yih K, et al. Varicella vaccination and ischemic stroke in children: Is there an association? Pediatrics 2009;123:e228.

29. Rowhani-Rahbar A, Klein NP, Dekker CL, et al. Biologically plausible and evidence-based risk intervals in immunization safety research. Vaccine 2012;31:271-7.

30. Tseng HF, Sy LS, Liu I, et al. Postlicensure surveillance for prespecified adverse events following the 13-valent pneumococcal conjugate vaccine in children. Vaccine 2013;31:2578-83.

31. Top KA, Constantinescu CM, Laflèche J, et al. Applicability of the Brighton Collaboration case definition for seizure after immunization in active and passive surveillance in Canada. Vaccine 2013;31:5700-5.

32. Mills E, Jadad AR, Ross C, et al. Systematic review of qualitative studies exploring parental beliefs and attitudes toward childhood vaccination identifies common barriers to vaccination. $J$ Clin Epidemiol 2005;58:1081-8.

33. Bardenheier B, Yusuf H, Schwartz B, et al. Are parental vaccine safety concerns associated with receipt of measles-mumpsrubella, diphtheria and tetanus toxoids with acellular pertussis, or hepatitis B vaccines by children? Arch Pediatr Adolesc Med 2004; 158:569-75.

34. MacDonald SE. Exploring the association between parental concern about vaccine safety and incomplete childhood immunization: a multivariate model [dissertation]. Edmonton (AB): University of Alberta; 2013.

35. Streng A, Liese JG. Decline of varicella vaccination in German surveillance regions after recommendation of separate first-dose vaccination for varicella and measles-mumps-rubella. Vaccine 2014;32:897-900.

36. Warden CR, Zibulewsky J, Mace S, et al. Evaluation and management of febrile seizures in the out-of-hospital and emergency department settings. Ann Emerg Med 2003;41:215-22.

37. von Spiczak S, Helbig I, Drechsel-Baeuerle U, et al. A retrospective population-based study on seizures related to childhood vaccination. Epilepsia 2011;52:1506-12.

Affiliations: Departments of Pediatrics (MacDonald) and Community Health Sciences (Simmonds, Svenson), University of Calgary, Calgary, Alta.; Faculty of Nursing (MacDonald) and School of Public Health (Svenson), University of Alberta, Edmonton, Alta.; and Epidemiology and Surveillance Team (Dover, Simmonds, Svenson), Alberta Ministry of Health, Edmonton, Alta.

Contributors: All authors contributed to the conception and design of the study. Douglas Dover and Lawrence Svenson conducted the analysis. All authors contributed to interpretation of the data. Shannon MacDonald drafted the article. All authors revised the article critically for important intellectual content, approved the version to be published and agree to be accountable for all aspects of the work in ensuring that questions related to the accuracy or integrity of any part of the work are appropriately investigated and resolved.

Funding: No direct funding was received for this study. Shannon MacDonald was supported by a Fellowship from the Canadian Institutes of Health Research and a Post-Doctoral Clinician Fellowship from Alberta Innovates-Health Solutions.

Acknowledgements: Shannon MacDonald would like to acknowledge the guidance and support of her postdoctoral supervisors, Dr. Suzanne Tough and Dr. Jim Kellner. The authors thank Florence Lai for her suggested improvements to the manuscript. 